\title{
PENGARUH ANALISIS JABATAN DAN ANALISIS PEKERJAAN TERHADAP KINERJA GURU SMP/MTS KECAMATAN LAMPIHONG KABUPATEN BALANGAN
}

\author{
JAMIL RIFANI \\ Sekolah Tinggi Ilmu Administrasi (STIA) Amuntai \\ Email : Jamilrifani75@gmail.com
}

\begin{abstract}
This study aims to determine the partial effect of job analysis and job analysis on the performance of SMP / MTs teachers in Lampihong District, Balangan Regency. The study sample numbered 85 people with a Porpusive Sampling technique ie the sample determined by researchers outside the informant was $<25 \%$ of all SMP / MTs teachers in Lampihong Subdistrict, Balangan Regency. The results of this study are (1) there is a significant influence between job analysis on the performance of SMP / MTs teachers in Lampihong Subdistrict Balangan Regency ( $t$-count $>t$-table value $=3,223>$ 1,890); there is a significant influence between job analysis on the performance of SMP / MTs teachers in Lampihong Subdistrict, Balangan Regency (t-count $>$ t-table value $=3,269>1,890)$; (3) job analysis and job analysis simultaneously affect the performance of teachers in the SMP / MTs of Lampihong Subdistrict of Balangan Regency (f-count> f-table value $=18.098>4.95)$; (4) job analysis has a dominant influence on teacher performance compared to job analysis (tcount job analysis $=3,269$, tcount job analysis $=3,223$ ).
\end{abstract}

Keywords: job analysis, job analysis, performance

\section{PENDAHULUAN}

Dalam rangka terus memacu usaha-usaha meningkatkan kinerja sesuai dengan pelaksanaan kerja aparatur pemerintah yang berorientasi pada Sumber Daya Manusia yang berkualitas, maka pembenahan terhadap jabatan yang diemban oleh aparatur pemerintahan diarahkan pada penataan pelaksanaan kerja. Peningkatan ini selain diarahkan pada mutu pelayanan terhadap masyarakat namun demikian secara umum kemampuan pegawai yang produktiflah yang mutlak dimiliki oleh setiap aparat pelaksana kerja bidang pemerintahan maupun pelayanan. Efektivitas kerja, efisiensi kerja dan disiplin kerja para pegawai termasuk sangat berperan untuk meningkatkan kinerja agar mampu memberikan kontribusi bagi perbaikan kinerja pegawai di lingkungan kerja masing-masing.

Kompleksitas pelaksanaan kerja Guru sekarang ini diarahkan pada pelayanan prima bidang pendidikan menengah, karenanya apabila dibutuhkan oleh masyarakat yang diayomi maka tingkat kesiapan untuk melakukan pelayanan semakin diperlukan, untuk itu perlu didukung oleh pemahaman terhadap tugas dan fungsi serta di mana dia ditempatkan sesuai dengan struktur organisasi sehingga memberikan pemeliharaan hubungan bagi publik. Sehubungan dengan hal tersebut guruguru SMP/MTs di Kecamatan Lampihong Kabupaten Balangan yang mempunyai tugas menyampaikan hasil analisis jabatan melalui 
analisis pekerjaan yang tepat agar setiap guru yang memiliki jabatan fungsional dilingkungan kerja mereka dapat menerapkannya sesuai dengan kebutuhan yang bersangkutan.

\section{TINJAUAN PUSTAKA}

\section{Analisis Jabatan}

Analisis jabatan merupakan proses pengkajian dan pengumpulan informasi yang berkaitan dengan pelaksanaan dan tanggung jawab suatu jabatan tertentu. Analisis jabatan dalam kenyataannya merupakan suatu prosedur untuk mengumpulkan, mengolah, menafsirkan dan menarik kesimpulan berdasarkan fakta yang relevan dengan jabatan secara sistematis.

\section{Analisis Pekerjaan}

Analisis pekerjaan adalah usaha yang sistematik dalam mengumpulkan, menilai, dan mengorganisasikan semua jenis pekerjaan yang terdapat dalam suatu organisasi. Berarti dalam suatu organisasi diperlukan keberadaan sekelompok analisis pekerjaan yang bertugas melakukan analisis terhadap semua pekerjaan yang ada.

\section{Kinerja}

Kinerja adalah perbandingan hasil yang dicapai dengan peran serta tenaga kerja persatuan waktu. Disamping itu kinerja yang dikaitkan dengan karyawan adalah hasil kerja secara kualitas dan kuantitas yang dicapai oleh seorang karyawan dalam melakukan tugasnya sesuai dengan tanggung jawab yang diberikan, tidak hanya bagi evaluasi kinerja pada akhir periode tapi juga untuk mengelola proses kerja selama periode tersebut.

\section{METODE PENELITIAN}

Berdasarkan tujuan penelitian, yaitu ingin menguji pengaruh analisis jabatan dan analisis pekerjaan terhadap kinerja guru, maka sifat penelitian ini dikategorikan penelitian penjelasan atau explanatory, di mana penelitian ini menjelaskan hubungan dan pengaruh melalui pengujian hipotesis. Jadi, jenis penelitian adalah penelitian explanatory yakni suatu jenis penelitian yang dipaparkan berdasarkan data perhitungan dari adanya pengaruh antar variabel independen dengan variabel independen antara analisis jabatan dan analisis pekerjaan terhadap kinerja guru SMP/MTs di Kecamatan Lampihong Kabupaten Balangan.

\section{Populasi dan Sampel Penelitian}

Populasi dalam penelitian ini adalah seluruh guru yang berjumlah 85 orang, karena sedikitnya jumlah populasi, maka penulis menggunakan teknik total sampling yakni seluruh populasi menjadi anggota yang akan diamati sebagai sampel, karena sampel yang besar cenderung memberikan atau lebih mendekati nilai sesungguhnya terhadap populasi atau dapat dikatakan semakin kecil pula kesalahan (penyimpangan terhadap nilai populasi). Populasi dalam penelitian ini adalah keseluruhan guru SMP/MTs di Kecamatan Lampihong Kabupaten Balangan yang berjumlah 85 orang. Penetapan responden dilakukan secara Porpusive Sampling yakni sampel yang ditetapkan peneliti di luar informan sejumlah $<25 \%$ dari keseluruhan guru SMP/MTs di Kecamatan Lampihong Kabupaten Balangan memiliki 2 sekolah yakni SMP Negeri 1 Lampihong, SMP Negeri 2 Lampihong dan MTs Negeri Lampihong sehingga berjumlah sebanyak 85 orang. Instrumen yang digunakan untuk penelitian ini adalah angket analisis jabatan dan analisis pekerjaan serta kinerja guru yang sudah memenuhi syarat validitas dan realibilitas. 


\section{HASIL DAN PEMBAHASAN}

Hasil dari analisa data adalah (1) Pengaruh analisis jabatan terhadap kinerja guru dengan menggunakan (uji t) yakni membandingkan antara nilai $\mathrm{t}_{\text {-hitung }}(\mathrm{th})$ dengan nilai $\mathrm{t}_{\text {-tabel }}(\mathrm{tt})$ pada taraf nyata (5\%). Hasil hitungan dijelaskan bahwa dari variabel analisis jabatan $\left(\mathrm{X}_{1}\right)$ yang mempunyai nilai $\mathrm{t}_{\text {-hitung }}>$ nilai $\mathrm{t}_{\text {-tabel }}=3.223>$ 1.890 berarti bahwa variabel tersebut pada taraf nyata $(5 \%)$ mempunyai pengaruh yang signifikan terhadap kinerja guru SMP/MTs Kecamatan Lampihong Kabupaten Balangan. Koefesien regresi faktor analisis jabatan $\left(\mathrm{X}_{1}\right)$ adalah sebesar 0,374, hal ini menunjukan hubungan positif atau searah dengan kinerja $\mathrm{Y}$. Angka $r^{2}$ untuk faktor analisis jabatan yang artinya bahwa faktor analisis jabatan terhadap kinerja guru SMP/MTs di Kecamatan Lampihong Kabupaten Balangan adalah 37,4 \% dengan catatan faktor lain adalah konstan.

Pengaruh analisis pekerjaan terhadak kinerja guru SMP/MTs di Kecamatan Lampihong Kabupaten Balangan, untuk menguji pengaruh variabel bebas yakni analisis pekerjaan $\left(X_{2}\right)$ terahdap variabel tergantung $(\mathrm{Y})$ dengan menggunakan uji parsial (uji t). Berdasarkan data yang diolah analisis pekerjaan $3.269>t_{\text {tabel }}$ sebesar 1.890 dengan probabilitas sebesar 0,000 lebih kecil dari $\alpha=0,05$ atau lebih besar dari taraf nyata $5 \%$. Hal ini menunjukan hubungan analisis pekerjaan $\left(\mathrm{X}_{2}\right)$ terhadap kinerja guru SMP/MTs Kecamatan Lampihong Kabupaten Balangan adalah signifikan. Koefesien regresi analisis pekerjaan $\left(\mathrm{X}_{2}\right)$ adalah sebesar 0,489 hal ini menunjukan hubungan positif atau searah dengan kinerja guru SMP/MTs di Kecamatan Lampihong Kabupaten Balangan (Y). Angka $r^{2}$ untuk faktor 0,489 artinya kontribusi analisis pekerjaan terhadap kinerja guru SMP/MTs Kecamatan Lampihong Kabupaten Balangan 48,9 \% dengan catatan faktor lain adalah konstan. (3) Untuk mengetahui pengaruh secara simultan analisis jabatan dan analisis pekerjaan dilakukan dengan menggunakan uji $f$ yakni dengan membandingkan $f_{\text {hitung }}$ dengan $f_{\text {tabel }}$ pada taraf nyata $\alpha=0,05$ dari hasil perhitungan data bahwa nilai $f$ hitung $18.089>f$ tabel 4,95 dengan probabilitas sebesar 0,000 , hal ini berarti bahwa taraf nyata $\alpha=0,05$ dapat dikatakan analisis jabatan $\left(X_{1}\right)$ dan analisis pekerjaan $\left(X_{2}\right)$ mempunyai pengaruh yang berarti terhadap kinerja guru SMP/MTs di Kecamatan Lampihong Kabupaten Balangan. Adapun besarnya kontribusi seluruh variabel analisis jabatan $\left(X_{1}\right)$ dan analisis pekerjaan $\left(X_{2}\right)$ ditunjukan dengan angka $r^{2}$ sebesar 0,365 . Angka ini mengandung arti bahwa seluruh variabel bebas (Analsisis Jabatan $\left(\mathrm{X}_{1}\right)$ dan Analisis Pekerjaan $\left(\mathrm{X}_{2}\right)$ ) yang digunakan untuk dalam persamaan regresi ini, secara serentak mampu memberikan kontribusi terhadap kinerja guru SMP/MTs di Kecamatan Lampihong Kabupaten Balangan sebesar 36,5 \% atau dengan kata lain secara serentak berpengaruh terhadap kinerja sebesar 36,5\% sedangkan sisanya $63,5 \%$ dipengaruhi oleh variabel lain diluar variabel yang ada terhadap kinerja. (4) Pengaruh dominan data yang diperoleh menunjukan bahwa pengaruh parsial terhadap variabel kinerja guru SMP/MTs di Kecamatan Lampihong Kabupaten Balangan adalah analisis pekerjaan yaitu sebesar 3.269. hal ini sesuai dengan nilai koefesien regresi variabel bahwa analisis pekerjaan yang memiliki nilai terbesar dibandingkan dengan variabel lainnya pada taraf nyata $\alpha=0,05$ mempunyai pengaruh secara dominan terhadap variabel kinerja guru SMP/MTs di Kecamatan Lampihong Kabupaten Balangan.

\section{KESIMPULAN}

Pada hasil analisis dan pembahasan pada bab sebelumnya, maka penelitian ini dapat ditarik beberapa kesimpulan, sebagai berikut

Analisis jabatan yang diberikan antara kinerja guru SMP/MTs se Kecamatan Lampihong 
Kabupaten Balangan terdapat pengaruh yang signifikan ( $t_{\text {hitung }}=3,223 . t_{\text {Tabel }}=1.890$ ). sedangkan analisis yang dilakukan melalui uji determinasi diketahui bahwa 0,374 artinya bahwa kontribusi faktor Analisis jabatan terhadap kinerja guru SMP/MTs se Kecamatan Lampihong adalah 37,04\% dengan catatan faktor lain adalah konstan.

Analisis pekerjaan yang diberikan antara kinerja guru SMP/MTs se Kecamatan Lampihong terdapat pengaruh signifikan ( $t_{\text {hitung }}=3.269$. $t_{\text {Tabel }}=1.890$ ), sedangkan analisis yang dilakukan melalui uji determinasi diketahui bahwa 0,489 artinya bahwa kontribusi Analisis Pekerjaan terhadap kinerja guru SMP/MTs se Kecamatan Lampihong adalah 48,9\% dengan catatan faktor lain konstan.

Secara simultan dari persamaan regresi dapat diketemukakan bahwa antara analisis jabatan dan analisis pekerjaan dengan kinerja guru SMP/MTs se Kecamatan Lampihong berpengaruh secara simultan dengan kinerja sekolah se Kecamatan Lampihong $\left(F_{\text {hitung }}=\right.$ 18.098, $\left.\mathrm{F}_{\text {Tabel }}=4.95\right)$.

Analisis pekerjaan mempunyai pengaruh yang dominan terhadap kinerja guru SMP/MTs se Kecamatan Lampihong dibandingkan dengan analisis jabatan $\left(t_{\text {hitung }}=\right.$ analisis pekerjaan 3.269 $>t_{\text {hitung }}$ analisis jabatan $=3.223$ ).

\section{DAFTAR PUSTAKA}

Achmad S. Ruky. (2003). SDM berkualitas: mengubah visi menjadi realitas. Jakarta: Gramedia Pustaka Utama.

Achmad S. Ruky. (2004). Sistem manajemen kinerja: panduan praktis untuk merancang dan meraih kinerja prima. Jakarta: Gramedia Pustaka Utama.
Anoraga, Pandji. 2001. Psikologi Kerja. Jakarta: Rineka Cipta.

Arikunto, Suharsimi. 2006. Manajemen Penelitian, Rineka Cipta, Yogyakarta.

Badan Nasional Sertifikasi Profesi (BNSP). (2005). Pedomana penyusunan standar kompetensi kerja. 